\title{
Desafio para a gestão ambiental integrada em território de fronteira agrícola no oeste do Pará*
}

\author{
Cristina Velásquez** \\ André Villas BOAS*** \\ Stephen Schiwartzman****
}

Sumário: 1. Introdução; 2. Caracterização socioambiental e política da região e modelo de ocupação; 3. Atores sociais e redes de atuação; 4. Estratégias de conservação ambiental e ordenamento territorial: o mosaico da Terra do Meio; 5. Conclusões.

SUMMARY: 1. Introduction; 2. Socio-environmental and political characterization of the region and occupation model; 3. Social actors and operation networks; 4. Environmental conservation and territorial organization strategies: Terra do Meio's mosaic; 5. Conclusions.

Palavras-chave: gestão integrada; conservação ambiental; populações tradicionais; áreas protegidas; Amazônia.

KEY WORDS: integrated management; environmental conservation; traditional populations; protected areas; Amazon region.

Este artigo aborda a Terra do Meio (PA), região brasileira localizada em um dos estados mais conflituosos da Amazônia, que tem se convertido em um desafio simbólico para a gestão pública integrada neste país. Ela está em um

\footnotetext{
* Artigo recebido em dez. 2005 e aceito em ago. 2006.

** Assessora de políticas públicas da ONG Instituto Socioambiental. Endereço: SCLN 210, bloco C, sala 112 - CEP 70862-530, Brasília, DF, Brasil. E-mail: crisvelasquez@socioambiental.org.br.

$* * *$ Coordenador do Programa Xingu da ONG Instituto Socioambiental. Endereço: Avenida Higienópolis, 901 — Higienópolis — CEP 01238-001, São Paulo, SP, Brasil. E-mail: vboas@socioambiental. org.br.

$* * * *$ Coordenador da ONG Environmental Defense. Endereço: 1875 Connecticut Avenue NW, Washington, DC, 20009, USA; e School of International Service, American University, 4400 Massachusetts Avenue, N.W. Washington, DC, 20008, USA. E-mail:steves@ed.org.
} 
contexto que traz elementos característicos de um complexo sistema geopolítico: grilagem de terras e exploração irracional dos recursos naturais; baixa presença do Estado; falta de integração das políticas públicas que incidem sobre o território. A existência de um movimento social estruturado e a intervenção de ONGs socioambientalistas na proteção e conservação da biodiversidade e das populações tradicionais (índios, ribeirinhos, seringueiros e agricultores familiares) formam o cenário em questão. Este artigo apresenta a caracterização socioambiental e econômica da região e discute o mosaico de unidades de conservação e o corredor de biodiversidade do Xingu como alternativas para um plano de ordenamento territorial como perspectiva de gestão integrada para a região.

\section{A challenge for integrated environmental management in agricultural frontier territory in western Pará, Brazil}

Terra do Meio, a region of the state of Pará, the most conflict-ridden in the Brazilian Amazon, presents an emblematic challenge for integrated public administration in the country, since it typifies characteristic frontier geopolitics: illegal occupation of public lands, irrational resource usage, absence of government, and inconsistent public policies for the region. The regional scenario includes an organized social movement, as well as NGOs supporting biodiversity protection and conservation and traditional populations (Indians, riparian communities, rubber tappers and family farmers). In this article, we present a socio-environmental and economic description of the region and discuss the reserves mosaic and Xingu biodiversity corridor as alternatives for integrated regional land use planning and management.

\section{Introdução}

A Terra do Meio, localizada no sudoeste do Pará, é uma vasta região com cerca de 7,9 milhões de hectares, encoberta em grande parte pela floresta Amazônica e representa cerca de $6 \%$ do território do estado. Abrange 38,62\% do município de Altamira, 19,25\% do município de São Félix do Xingu e uma pequena parte do município de Trairão. Trata-se de uma região com baixa densidade populacional e isolada, mas que serviu durante quase um século à extração e produção de látex natural, passando pelos ciclos da castanha, do ouro e da retirada de pele de onça para exportação na década de 1970. Entretanto, a exploração da borracha, a partir do final do século XIX, foi o maior dos fenômenos econômicos, repercutindo na produção nacional. O nome Terra do Meio deve-se ao fato da região se encontrar no interflúvio dos rios Xingu e Iriri. 
A partir de 1990, a região, irrigada pelo rio Xingu ${ }^{1}$ (Médio Xingu) e inúmeros igarapés que formam alguns dos seus afluentes, como o Riozinho do Anfrísio, e rios Curuá, Iriri e Rio Novo, transformou-se em alvo de conflitos de terra e de disputa pela riqueza de seus recursos naturais, sem que houvesse controle algum por parte do governo federal.

Está inserida dentro de um conjunto maior de áreas protegidas que estamos chamando de Corredor da Bacia Hidrográfica do Xingu com mais de 26 milhões de hectares e que reúne um conjunto de 18 terras indígenas (24 etnias) que constitui um mosaico de unidades de conservação de proteção integral $^{2}$ e uso sustentável ${ }^{3}$ identificadas como áreas de alta importância para a conservação da biodiversidade. Circundada pelas rodovias BR 163 e BR 230 (rodovia Transamazônica), abriga nos municípios que surgiram toda a população de migrantes nordestinos que vieram para atuar como soldados da borracha, cerca de 11 mil habitantes. Alguns desses municípios são vetores de migração e pressão sobre a Terra do Meio, seja para a exploração legal e ilegal dos recursos naturais, seja para a especulação de terras públicas e privadas.

Sem a presença do Estado e com a falta de ações governamentais claras, a região é alvo direto de ações ilícitas como a grilagem de porções de terra do tamanho de países europeus inteiros com apoio dos cartórios municipais, a exploração predatória do mogno, o trabalho escravo em grandes fazendas, a rota do tráfico de drogas, a instalação irregular de pistas de pouso e a pecuária extensiva.

O cenário que se coloca para a Terra do Meio é revelador e simbólico para outras partes da Amazônia e do Brasil, já que traz elementos que refletem a situação de isolamento e a falta de governança ${ }^{4}$ na região. Se de um

1 O rio Xingu nasce no Planalto dos Guimarães (Mato Grosso) e deságua no rio Amazonas (Pará), formando uma das maiores bacias hidrográficas do Brasil, com 511.891,00 milhões de ha de superfície, dos quais 65\% estão no Pará.

${ }^{2}$ UC de proteção integral: grupo de UCs de uso restrito para a preservação da biodiversidade onde não é permitida a presença de moradores em suas áreas. Pertencem a esse grupo as categorias parque nacional, reserva biológica, estação ecológica, refúgio de vida silvestre, áreas assim determinadas pelo Snuc — Sistema de Unidades de Conservação (Lei no 9.987 de 2000).

${ }^{3}$ UCs de uso sustentável: grupo de UCs que permitem o uso sustentável dos recursos naturais e, portanto, a possibilidade de existirem populações vivendo dentro das áreas. Nesse grupo estão as reservas extrativistas, reservas de desenvolvimento sustentável, florestas nacionais, áreas de proteção ambiental (APAs), também determinadas pelo Snuc (Lei no 9.987 de 2000).

${ }^{4}$ Utilizamos neste artigo o conceito de governança empreendido por Graham, Amos e Plumptre (2003) como "a interação entre estruturas, processos e tradições que determina como o poder e as responsabilidades são exercidos, como decisões são tomadas e como os cidadãos e outros parceiros envolvidos (stakeholders) são ouvidos". Diz respeito fundamentalmente às relações de poder e responsabilidade, definindo como são tomadas as decisões em assuntos de interesse coletivo, quem tem poder de decidir, quem influencia nas decisões, e como são estabelecidas as responsabilidades dos tomadores de decisão. 
lado temos um quadro tão complexo de pressões e conflitos sociais e presença forte do movimento social, de outro, deveríamos contar com um plano de ordenamento territorial e gestores públicos bem preparados, aptos a enfrentar a situação. Este artigo tem o objetivo de apresentar os elementos que compõem o cenário em questão e discutir sobre os possíveis caminhos para a gestão do território. Como alternativa, veremos a figura do mosaico de unidades de conservação e seus mecanismos de gestão. $\mathrm{O}$ artigo está dividido em itens: caracterização socioambiental da região e as políticas que incidem sobre o território; os diferentes atores que compõem o cenário, as estratégias de conservação ambiental e as perspectivas existentes.

\section{Caracterização socioambiental e política da região e modelo de ocupação}

A extensa rede de rios e igarapés que atravessa a região favoreceu a exploração pontual de seus interiores, onde se localizam jazidas minerais, principalmente de ouro e estanho, e as áreas de concentração do mogno. Ao longo da rodovia BR 163 (Cuiabá-Santarém) e da BR 230 (Transamazônica), novos municípios se desenvolveram, dos quais sete, além de Altamira, São Félix do Xingu e Trairão, exercem certa influência econômica sobre a região.

A Terra do Meio é, portanto, uma das regiões onde há uma grande lacuna do conhecimento científico, ao mesmo tempo em que está submetida a fortes pressões, por estar situada entre alguns dos principais eixos de desenvolvimento na Amazônia brasileira. O bom estado de conservação se deve, em parte, ao conjunto de terras indígenas no seu entorno. Uma situação ímpar em relação às demais regiões de fronteira do país e que merece atenção especial em políticas ambientais. No restante da região, as áreas de terra firme situadas no interflúvio Xingu-Iriri sofreram impactos pontuais com a retirada de mogno.

Por outro lado, esse status de conservação também se deve à força dos movimentos sociais locais, sediados em grande parte em Altamira, que vêm se ocupando do futuro dos produtores rurais em áreas de colonização da Transamazônica, mas, também, do futuro da bacia do rio Xingu e da floresta Amazônica. Assim, vêm atuando também na linha dos direitos humanos para proteger lideranças locais que se opõem à grilagem sem limites e à exploração das populações locais e do trabalho escravo em fazendas da região. 


\section{Dinâmica de desmatamento}

A iniciativa de proteção da Terra do Meio faz parte da agenda do movimento social do Pará desde a década de 1970. Apenas recentemente, e pelo resultado dos estudos de Macapá (ISA, 1999), houve o compromisso dos governos federal e estadual na criação de um mosaico de áreas protegidas para a região, atendendo a essa luta histórica pela proteção das comunidades locais que ali vivem e dos recursos naturais. A região era considerada por Ademir Federicci, Dema e outros líderes do MDTX (Movimento pelo Desenvolvimento da Transamazônica e Xingu), como os dois "pulmões verdes" do Pará.

A esse movimento social agregaram-se forças de ONGs socioambientalistas como é o caso do Instituto Socioambiental (ISA), Environmental Defense, junto com a Comissão Pastoral da Terra-Xingu e Fundação Viver, Produzir e Preservar (FVPP), que têm apoiado a parte de organização comunitária, infra-estrutura para as comunidades, o monitoramento via sensoriamento remoto dos vetores de ocupação e desmatamento e, principalmente, realizado o trabalho de articulação política junto ao governo federal para a criação e implementação efetiva das unidades de conservação criadas. Esse grupo se mobilizou para reunir outras instituições que atuam ou têm interesse em atuar na região como o Instituto de Pesquisa Ambiental na Amazônia (Ipam), WWF-Brasil e Conservation International-Brasil e formaram a rede de ação pela Terra do Meio, somando esforços para realizar um planejamento integrado das ações vindas da sociedade civil e de discutir projetos governamentais que tenham influência sobre a área, como as grandes obras de infra-estrutura.

A resistência a esses projetos não se dá em oposição ao desenvolvimento econômico regional, mas aos impactos sociais e ambientais gerados por esses vetores de ocupação, sem um plano de ordenamento territorial regional, calcado em zoneamentos agroecológicos e econômicos com perspectiva de desenvolvimento sustentável. Nesses casos, tem sido questionada a sustentabilidade de modelos econômicos baseados estritamente em projetos desenvolvimentistas, tais como as barragens do Complexo Hidrelétrico de Belo Monte, a expansão do cultivo da soja na Amazônia e o extrativismo madeireiro.

No entanto, a situação nos últimos anos tem demonstrado que a grilagem de terras e a exploração dos recursos naturais tem aumentado de maneira gritante. Do mesmo modo que a afronta aos direitos humanos, haja vista o número de 37 lideranças sindicais e de seus defensores assassinados nos últimos anos na região, entre eles a missionária irmã Dorothy e os líderes comunitários Dema e Brasília. 
De acordo com os dados de desmatamento monitorados pelo ISA em dois períodos distintos, 2002-04 e 2004/05, observou-se um aumento de 61\% e $36 \%$, respectivamente, das taxas de desmatamento.

A comparação de dados entre os períodos demonstra que a criação das unidades de conservação teve um impacto positivo significativo, com conseqüente diminuição de invasão nas áreas de ocupação. Mas, ainda assim, o desmatamento continua existindo, como mostra a tabela 1.

\begin{tabular}{|c|c|c|c|c|c|c|}
\hline \multicolumn{6}{|c|}{ Tabela 1} & Desmatamento nas UCs federais \\
\hline & Área & Desma & nento & & & \\
\hline UCs federais & (ha) & Até 2002 & $2002-04$ & $\%$ & $2004 / 05$ & $\%$ \\
\hline Esec da Terra do Meio & $3.373 .110,0$ & $8.088,93$ & $31.218,87$ & 385,95 & $11.199,39$ & 35,87 \\
\hline Parna da Serra do Prado & $445.392,0$ & $4.226,37$ & $19.338,96$ & 457,58 & $2.708,55$ & 14,01 \\
\hline $\begin{array}{l}\text { Resex Riozinho do } \\
\text { Anfrísio }\end{array}$ & $736.340,0$ & $1.068,82$ & 685,72 & 64,16 & $1.358,49$ & 198,11 \\
\hline Resex do Iriri & $396.966,74$ & $6.731,40$ & $1.251,67$ & 113,67 & $3.227,00$ & 257,82 \\
\hline
\end{tabular}

Isso comprova denúncias feitas pela população local da retomada das invasões nos últimos meses nas fazendas existentes dentro da área da Resex do Iriri, como a da fazenda Bacuri. Inclusive os dados vistos na imagem de satélite no período de 2004/05 reafirmam essa tendência, pois apesar da criação das áreas ter espantado muitos grileiros e madeireiros, outros ainda estão instalados naquela região.

Quanto às terras indígenas, o desmatamento foi pouco significativo, como podemos ver na tabela 2 , o que demonstra a importância dessas áreas para a conservação de todo o mosaico. Apesar disso, observamos a necessidade de proteção e fiscalização de demarcação definitiva de algumas áreas, a fim de conter os eventuais desmatamentos ilegais, como mostra a tabela 1 . 
Tabela 2

Desmatamento nas terras indígenas

\begin{tabular}{|c|c|c|c|c|c|c|}
\hline \multirow[b]{2}{*}{ Terra indígena } & \multirow{2}{*}{$\begin{array}{l}\text { Área } \\
\text { (ha) }\end{array}$} & \multicolumn{2}{|c|}{ Desmatamento (ha) } & \multirow{2}{*}{\multicolumn{2}{|c|}{$\begin{array}{c}\text { Desmatamento (ha) } \\
2004 / 05\end{array}$}} & \multirow[b]{2}{*}{$\%$} \\
\hline & & Até 2002 & 2002-04 & & & \\
\hline TI Kuruáya & 166.700 & 490,13 & 0,00 & 0,00 & 0,00 & 0,00 \\
\hline $\begin{array}{l}\text { TI Xipaya } \\
\text { (com reducão) }\end{array}$ & 178.624 & 279,92 & 28,78 & 10,28 & 32,22 & 111,96 \\
\hline
\end{tabular}

Nas unidades de conservação em vias de criação, observa-se que houve aumento significativo do desmatamento nos períodos, especialmente na região da futura APA e da floresta estadual do Iriri, com aumento de mais de $100 \%$ de novas áreas ocupadas, como mostra a tabela 3.

\begin{tabular}{|c|c|c|c|c|c|c|}
\hline \multirow[b]{3}{*}{ TM } & \multicolumn{4}{|c|}{$\begin{array}{l}\text { Tabela } 3 \\
\text { as UCs em vias de criação }\end{array}$} & & \multirow[b]{3}{*}{$\%$} \\
\hline & \multirow{2}{*}{$\begin{array}{c}\text { Área total } \\
\text { da TM } \\
\text { (ha) }\end{array}$} & \multicolumn{2}{|c|}{ Ocupação (ha) } & \multirow{2}{*}{\multicolumn{2}{|c|}{$\begin{array}{c}\text { Ocupação } \\
\text { (ha) } \\
2004 / 05\end{array}$}} & \\
\hline & & Até 2002 & $2002-04$ & & & \\
\hline APA & $1.711 .147,05$ & $112.562,29$ & $137.085,89$ & 121,79 & $50.190,45$ & 36,61 \\
\hline $\begin{array}{l}\text { Floresta estadual } \\
\text { do Iriri }\end{array}$ & $5.449 .887,97$ & $14.476,84$ & $52.682,57$ & 363,91 & $17.204,21$ & 32,66 \\
\hline Resex Xingu & $307.077,93$ & $1.382,57$ & $1.571,57$ & 113,67 & $1.092,33$ & 69,51 \\
\hline
\end{tabular}

Quanto aos vetores de desmatamento foram identificados focos ao longo dos rios, entre as áreas da Resex Riozinho do Anfrísio e Resex do Iriri e na Esec Terra do Meio e Parna Serra do Pardo. Na maioria das áreas, os focos estão nas fazendas já existentes e que, de certa maneira, não pararam a atividade de abertura de novas áreas. Isso indica que a fiscalização deve ser mais intensa e contínua para demonstrar a ação do governo. 


\section{Mosaico da Terra do Meio}

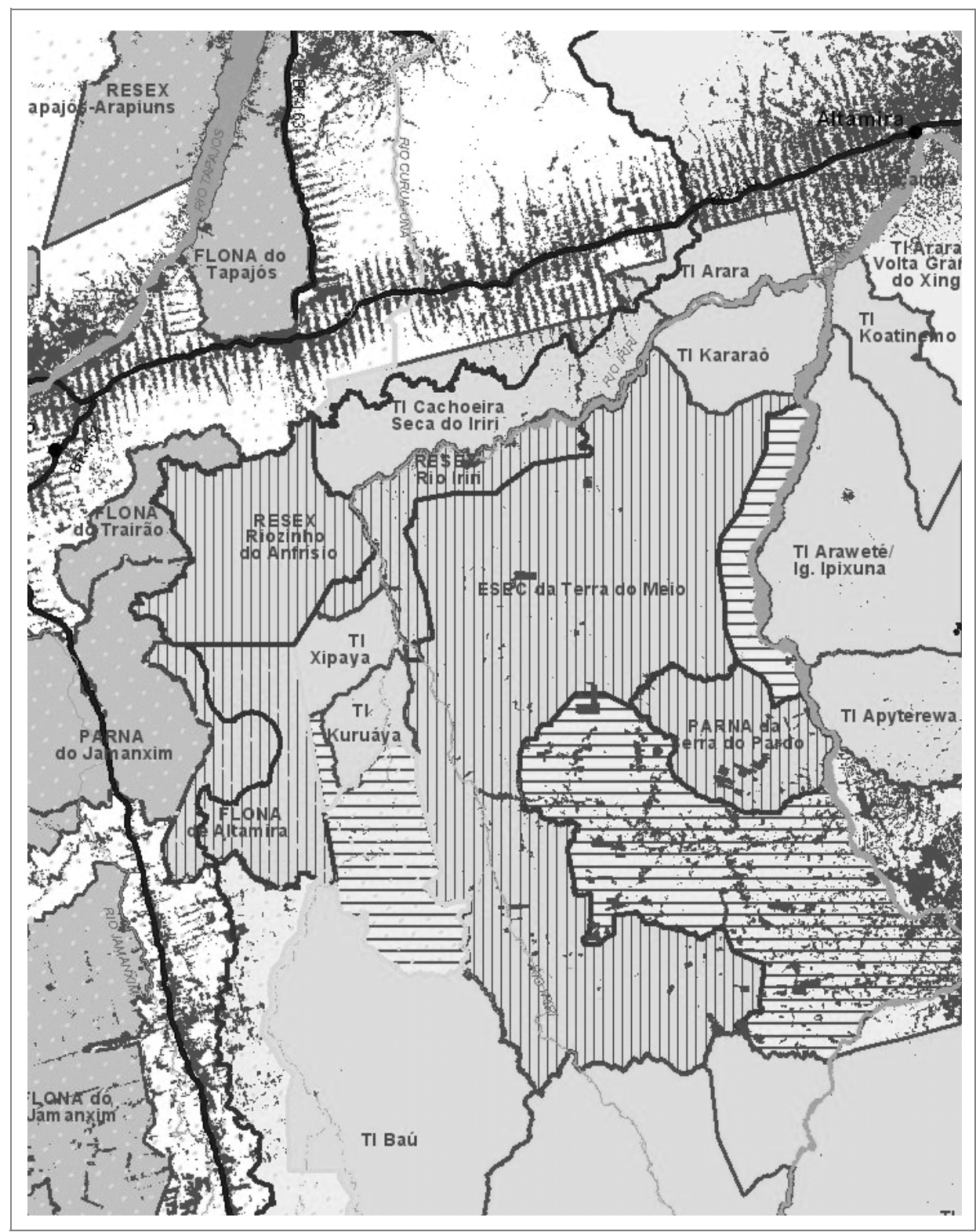

Fonte: Laboratório de Geoprocessamento do Instituto Socioambiental, out. 2006. 


\section{Atores sociais e redes de atuação}

A abertura da estrada da Companhia Mineradora Canopus, que explorou cassiterita em meados dos anos 1980, permitiu a entrada das madeireiras, de levas de migrantes e a formação de vários núcleos populacionais. Entre os anos 1998 e 2000, teve início um novo ciclo de atividades, dessa vez de fazendeiros, especuladores e pecuaristas que se apropriaram da terra, utilizando a densa rede de estradas deixada pelas madeireiras, acelerando a ocupação da região. As vilas e pequenos núcleos populacionais surgiram a partir de 1992, concentrando em seu entorno famílias de colonos, que adquiriram terras por meio do Iterpa ou compra de terceiros. Devido a um acordo entre o Iterpa (Instituto de Terras do Pará) e os colonos, as pequenas propriedades se estabeleceram a uma distância de até $10 \mathrm{~km}$ da estrada da Canopus, com um tamanho médio de 100 ha (Amaral e Escada, no prelo). O acordo não foi legitimado e a posse da terra dos colonos não foi legalizada, facilitando o estabelecimento de fazendas de médio e grande portes misturadas às propriedades dos colonos, cujas terras foram adquiridas muitas vezes por meio de invasão, compra e agregação de lotes dos pequenos produtores rurais.

De acordo com Aguiar (2005), são cinco os tipos de atores na região:

v fazendeiros - proprietários de grandes e médias fazendas, de tamanho superior a 2.500 ha, com relato de fazendas de até 50 mil ha. A maioria dos fazendeiros desenvolve atividades ligadas à pecuária e alguns deles têm envolvimento com atividades ilícitas como narcotráfico, grilagem, trabalho escravo e desmatamento ilegal. Distribuem-se ao longo dos ramais/ linhas transversais à estrada da Canopus e em áreas remotas, distantes das estradas principais e de difícil acesso;

v colonos - pequenos agricultores que desenvolvem atividades ligadas à agricultura de subsistência cujo modo de produção baseia-se na mão-deobra familiar. As propriedades variam de tamanho, em média de 50 ha a 100 ha podendo chegar até a cerca de 300 ha, o que é raro pelas dificuldades em se manter a terra livre de invasões e grilagem;

v colonos que não utilizam mão-de-obra externa - produtor rural que não depende da mão-de-obra familiar, possuindo outras fontes de renda. Desenvolvem atividades associadas à criação de gado e à especulação da terra. Como os colonos, distribuem-se ao longo da estrada da Canopus e nos 
assentamentos do Iterpa. O tamanho das propriedades pode variar de 100 ha a 2.500 ha;

v população ribeirinha - localizam-se nas margens dos rios Xingu, Iriri e Curuá, em habitações isoladas umas das outras. São cerca de 300 famílias moradoras das Resex do Iriri, Resex do Riozinho do Anfrísio e também das áreas onde foi criada a Estação Ecológica Terra do Meio e o Parque Nacional da Serra do Pardo. Ainda existem ribeirinhos na área onde pretende ser homologada a Terra Indígena Cachoeira Seca;

v população indígena - a região está rodeada por um conjunto de nove terras indígenas, além do complexo de terras dos kayapó mais ao longo da bacia hidrográfica do Xingu. Tem desempenhado o papel fundamental de proteção e conservação de seus territórios, que permanecem com baixos indicadores de desmatamento.

Ainda nesse território outros tipos de atores têm atuação ativa, que são os movimentos sociais locais como o MDTX - Movimento pelo Desenvolvimento da Transamazônica e Xingu, que surgiu dos movimentos populares na região e tem como bandeira o apoio à agricultura familiar, no que se refere à formação de quadros e ao ordenamento territorial a favor do desenvolvimento sustentável justo; a FVPP - Fundação Viver, Produzir e Preservar, que congrega cerca de 115 associações de base de agricultores familiares que fazem parte desse grupo maior; a CPT - Comissão Pastoral da Terra, com escritórios nos municípios de Tucumã, São Félix do Xingu e Altamira, trabalha com foco no apoio às populações tradicionais e agricultores familiares da região no apoio aos direitos humanos e à luta política pela conquista dos direitos de cidadania; as ONGs nacionais que atuam na região, como o ISA Instituto Socioambiental, que atua na implementação do mosaico de unidades de conservação, o Ipam e outras, como a WWF-Brasil, que têm interesse em atuar na região.

Essas ONGs se reuniram em maio último para formar uma coalizão/ rede de apoio à criação do mosaico da Terra do Meio, para efetivar a criação das áreas e iniciar um planejamento integrado de ações com vistas à gestão desse território.

Algumas políticas públicas incidem na região e têm interface com as questões ali debatidas, como é o caso da pavimentação da rodovia BR 163 e do Plano da BR 163 Sustentável, que deram subsídios para a criação do primeiro distrito florestal brasileiro.

Outras políticas públicas existentes são o Plano Nacional de Áreas Protegidas (Pnap), o Plano de Combate ao Desmatamento e a Política Nacional 
de Populações Tradicionais. Esta última está sendo preparada e deverá ser publicada até o final deste ano.

A recém-aprovada Lei de Gestão de Florestas Públicas estabelece as concessões florestais para empresas nacionais e comunidades rurais da Amazônia para o manejo florestal de áreas em períodos de até 40 anos. Ela ainda é muito nova, mas pretende ser colocada em prática nas florestas nacionais e considerando que o mosaico da Terra do Meio será composto de uma floresta estadual, a do Iriri, e é vizinho da Floresta Nacional de Altamira, essa região também será alvo dessa política.

Além dessas políticas, existe uma série de outros projetos que têm seu recorte geográfico incidindo sobre a região, mas, uma vez que esses programas não são planejados de maneira integrada entre os ministérios, não necessariamente existem ações complementares e conjuntas e acaba se tornando mais um problema do que uma solução.

\section{Estratégias de conservação ambiental e ordenamento territorial: o mosaico da Terra do Meio}

Após a morte da missionária americana Dorothy Stang, coincidentemente a região passou de esquecida e abandonada pelo poder público a alvo de um conjunto de ações para proteger o território que já vinham sendo planejadas.

A iniciativa de proteção da Terra do Meio faz parte da agenda do movimento social do Pará desde a década de 1990, mas apenas recentemente e ancorado pelo resultado dos estudos de Macapá (ISA, 2001) houve o compromisso dos governos federal e estadual na criação de um mosaico de áreas protegidas para a região, vindo atender a essa luta histórica pela proteção das comunidades locais e dos recursos naturais.

O início da implantação do mosaico da Terra do Meio se deu em fevereiro de 2005, com a criação pelo governo brasileiro de 4,5 milhões de ha de novas áreas protegidas na região da Terra do Meio. Com a Resex Riozinho do Anfrísio e a Resex do Iriri (criada em junho de 2006), o mosaico da Terra do Meio agora tem um total aproximado de 5,2 milhões de ha. O governo do estado do Pará preparou e realizou audiências públicas para a criação da APA Triunfo do Xingu e da Floresta Estadual do Iriri até o final do ano, completando cerca de 7 milhões de ha do mosaico de UCs.

Entretanto, ainda falta a criação das unidades de conservação Resex do Médio Xingu, federal; e área de proteção ambiental de São Félix do Xingu, estadual; e Floresta Estadual do Iriri, extremamente necessárias para completar o mosaico de áreas protegidas da Terra do Meio. 
O mosaico de unidades de conservação é uma categoria de proteção prevista pela Lei $\mathrm{n}-9.985$ de julho de 2000, o Snuc - Sistema Nacional de Unidades de Conservação, regulamentado em agosto de 2002, reconhece a categoria e prevê a criação de um conselho gestor do mosaico como instância de apoio à gestão das unidades que o compõem. No entanto, não existe regulamentação jurídica específica para a formação do mosaico. No Brasil existem até o momento apenas dois mosaicos reconhecidos pelo poder público, um no Piauí e outro na Mata Atlântica, entre São Paulo e Paraná.

A figura do mosaico de UCs traz a perspectiva de gestão do território, mas não prevê mecanismos claros de como deve funcionar na prática.

De acordo com o Snuc, na definição de mosaico aparece a figura dos corredores ecológicos, ainda em uma perspectiva de corredor que interliga diferentes áreas, fazendo o papel de corredor de fauna e de possibilitador do fluxo gênico de espécies. Entretanto, o governo brasileiro tem utilizado o conceito de corredor ecológico para definir gestão de grandes áreas ou territórios; nesse contexto é que surge o conceito de corredor de biodiversidade.

A situação fundiária conflituosa, criada pelas fraudes, fica ainda pior num cenário em que pouco tem sido feito pelo poder público para desenvolver na região qualquer política pública coordenada de ordenamento territorial. Muitas vezes, a falta de organização dos arquivos oficiais, como os do Instituto Nacional de Colonização e Reforma Agrária (Incra) e do Instituto de Terras do Pará (Iterpa), não permite definir com certeza o status de certas áreas. Em muitas delas, os processos de titulação estão inacabados ou as informações referentes a eles foram perdidas. Para se ter uma idéia do problema, segundo estudo feito pelo ISA em 2003, existem hoje na região áreas sobrepostas, com dupla titulação; com titulação definitiva, mas com procedimentos administrativos duvidosos; com domínio indefinido ou desconhecido; e ainda aquelas em litígio, sendo que muitas delas com mais de um desses problemas.

Quando o tema é regularização fundiária, muito pouco se tem avançado sobre o assunto, ficando os gestores públicos do Ibama destinados a cuidar da região. Não são mais que cinco funcionários recém-contratados que se revezam para visitar as áreas periodicamente e gerir os mais de 5 milhões de hectares, sem muitos recursos para negociar e convencer os comunitários, índios e grileiros nessa disputa territorial. Existe pouco ou muito pouco envolvimento dos governos locais e estadual na gestão dessas áreas e no apoio aos serviços básicos para essas populações, uma vez que as unidades são federais e inexistem mecanismos de responsabilidade compartilhada entre governos no que se refere à conservação ambiental.

Um dos exemplos mais extremos da ocupação irregular é o caso do megaempresário Cecílio Rego de Almeida, que se diz dono de cerca de 4,7 milhões de 
hectares na região sobrepostos às Resex do Riozinho do Anfrísio e do Iriri, à toda extensão da Floresta Nacional de Altamira, a dois assentamentos do Incra, à área prevista para a Floresta Estadual do Iriri e às terras indígenas Xypaia, Curuaya e Baú. A "Ceciliolândia", como já foi apelidada, equivale a duas vezes o território da Bélgica. Nos últimos anos vem expulsando ribeirinhos de suas terras e ocupando-as ilegalmente com um conjunto de benfeitorias.

O corredor de biodiversidade do Xingu compreende um conjunto de diferentes ecossistemas, desde o cerrado e florestas de transição até a floresta densa, e encontra-se ao longo de uma das mais ativas regiões do arco do desmatamento. Na visão do limitado conhecimento científico sobre os ecossistemas amazônicos, áreas extensas são requeridas para manter a viabilidade de populações de grandes mamíferos e frear ações de desmatamento e degradação; assim, muitos cientistas acreditam que as megarreservas são hoje de alta prioridade para a conservação na Amazônia (Peres, 2000).

Enquanto certos recursos existem no Programa Arpa/MMA para a implementação de unidades de conservação de proteção integral na Terra do Meio, os recursos humanos isoladamente são inadequados para assegurar isso. Com essa ausência de recursos financeiros e humanos do governo, o monitoramento e controle das terras indígenas (a preponderância do corredor) são, na atualidade, praticamente financiados por ONGs.

Nenhuma agência governamental vê a integridade e sustentabilidade do corredor do Xingu a longo prazo como parte de seu mandato, entretanto, a interdependência dessas reservas, particularmente aquelas rio abaixo, é evidente. A Funai e o Ibama, ao contrário, têm historicamente olhado entre si com desconfiança e suspeita. As ameaças ao corredor são enormes e tendem a aumentar. Exercícios de modelagem para o desmatamento futuro na região (Soares et al., 2006) apostam pesadamente na integridade das áreas protegidas, particularmente as terras indígenas, próximas a rodovias, e as mais remotas, em um cenário com governança, ou seja, aquele em que existe apoio ao fortalecimento organizacional às instituições de base e protagonismo nos espaços de discussão das políticas públicas. Entretanto, esse modelo está baseado na atuação histórica das terras indígenas, enquanto barreira para o desmatamento e incêndios, que representam mais de 1 milhão de $\mathrm{km}^{2}$ na Amazônia brasileira realizando a função de importante barreira contra o avanço da fronteira agrícola (Nepstad et al., 2006).

As pressões sobre as reservas deverão aumentar. As comunidades indígenas e tradicionais necessitarão melhorar a capacidade de monitoramento e controle de suas fronteiras, melhorar o relacionamento efetivo com todos os níveis de governo, ter acesso a serviços sociais básicos e desenvolver alternativas econômicas sustentáveis para continuar defendendo a integridade ecológica de suas terras. 


\section{Conclusões}

A grande questão colocada aqui é a necessidade de reunir diferentes mecanismos que apóiem a gestão integrada da terra para, além do governo federal e do Ministério do Meio Ambiente, integrar governos estaduais e municipais e estabelecer uma estratégia definida no combate ao desmatamento e à grilagem naquelas terras.

Para tanto, é necessário buscar compreender e integrar os diferentes atores sociais que atuam na região, com seus distintos interesses, para que possam se preparar para enfrentar esse desafio. Ressaltamos que a decretação das áreas já criadas, sem ações de fiscalização e regularização fundiária, não garante a conservação de suas riquezas, menos ainda a proteção do território e das comunidades locais diante das pressões existentes naquela região.

Outra questão relevante é saber em que medida os gestores públicos estão sendo preparados para enfrentar essa situação e de que maneira o governo vem tratando essas situações isoladas como um modelo para o desenvolvimento do ordenamento territorial e de gestão para aquelas áreas. Historicamente, o que se tem visto é que as particularidades históricas, culturais e os conflitos sociais têm sido encarados pelo poder público como obstáculos que desviam o caminho do que se entende por gestão de áreas públicas conservadas e não como uma oportunidade de refletir e referendar novos princípios e estratégias para os caminhos da conservação ambiental no Brasil.

Assim, o mosaico da Terra do Meio e o corredor de biodiversidade do Xingu representam um avanço significativo do envolvimento do movimento social na luta pela preservação ambiental e na definição de uma estratégia de conservação. A opção do governo de criar novas unidades de conservação extensas em regiões de conflito, como a Terra do Meio, reflete uma antiga reivindicação dos movimentos sociais. Ao mesmo tempo, as limitações institucionais dos órgãos governamentais competentes perante as dimensões geográficas e a velocidade dos processos econômicos informais, se não ilegais, dominantes na região, põem em risco os recentes avanços ambientais e sociais. São necessárias parcerias operacionais entre governos, movimentos sociais e ONGs para viabilizar mecanismos efetivos de gestão dos referidos espaços.

\section{Referências bibliográficas}

AGUIAR, A. P. Processo de ocupação nas novas fronteiras na Amazônia: o interflúvio Xingu-Iriri. Revista Estudos Avançados, v. 19, n. 54, 2005. 
AMARAL, S.; ESCADA, M. I. S. E. Dinâmica territorial e socioambiental das frentes de ocupação e áreas consolidadas: o caso de São Félix do Xingu e da Frente Iriri. São José dos Campos: Inpe. Relatório técnico. prelo.

CPT (COMISSÃO PASTORAL DA TERRA). Relatório sobre os crimes do latifúndio. Disponível em: <www.social.org.br/relatoriolatifundio2003.htm>. Acesso em: ago. 2003.

Relatório sobre os crimes do latifúndio. Disponível em: <www.social.org.br/ relatoriolatifundio2003.htm>. Acesso em: 2006.

FEARNSIDE, P. M. Conservation policy in Brazilian Amazonia: understanding the dilemmas. World Development, n. 31, p. 757-779, 2003.

ISA (INSTITUTO SOCIOAMBIENTAL). Projeto realização de estudos preliminares e formulação de uma proposta técnica para a implantação de um mosaico de unidades de conservação no Médio Xingu. Brasília: ISA/MMA, 2003.

Campanha Y'Ikatu Xingu: o rio Xingu e a região. Disponível em: <www.yikatuxingu.org.br/pgn/rioxingueregiao.html>. Acesso em: 1 dez. 2006.

—; IMAZON (INSTITUTO DO HOMEM E DO MEIO AMBIENTE DA AMAZÔNIA), ISPN (INSTITUTO SOCIEDADE, POPULAÇÃO E NATUREZA), GTA (GRUPO DE TRABALHO AMAZÔNICO); CI (CONSERVATION INTERNATIONAL). Avaliação e identificação das ações prioritárias da conservação, utilização sustentável e repartição dos benefícios da biodiversidade da Amazônia. In: SEMINÁRIO DE CONSULTA MACAPÁ. Anais... São Paulo, Brasil: ISA, 1999.

GRAHAM, J.; AMOS, B.; PLUPTRE, T. Governance principles for protected areas in the 21st century. Durban: UICN, 2003.

NEPSTAD, D. et al. Inhibition of Amazon deforestation and fire by parks and indigenous lands. Conservation Biology, n. 20, p. 65-73, 2006.

PERES, C. A. Why we need mega-reserves in Amazonia. Conservation Biology, 2000.

ROLLA, A.; RICARDO, F. P. Amazônia brasileira 2004. São Paulo: Instituto Socioambiental, 2004.

SCHWARZMAN, S. Extractive reserves: the rubber tappers' strategy for sustainable use of the Amazon rainforest. In: BROWDER, J. O. (Ed.). Fragile lands in Latin America, Boulder, CO: Westview Press, p. 150-165, 1985.

SCHMINCK, M.; WOOD, C. H. Contested frontiers in Amazonia. New York, NY: Columbia University Press, 1992.

SOARES-FILHO, B. S. et al. Modelling conservation in the Amazon basin. Nature, n. 440, p. 520-523, 2006.

TERBORGH, J. The fate of tropical forests: a matter of stewardship. Conservation Biology, n. 14, p. 1358-1361, 2000. 